\title{
Relação entre a percepção de qualidade e a classe econômica em serviço odontológico
}

\author{
Andrea Dornelles Fittipaldi ${ }^{1}$ \\ Carolina Lopes Araujo ${ }^{2}$
}

\section{Resumo}

No setor de serviços, o desafio para fidelizar clientes é grande devido às suas características de intangibilidade, inseparabilidade, variabilidade e perecibilidade. No setor odontológico, a dificuldade é ainda maior. A fidelização depende da satisfação do paciente e o conjunto de experiências de satisfação do paciente forma a sua percepção de qualidade. Neste estudo, foi utilizado o modelo de Parasuraman, Zeithaml e Berry (1991), segundo o qual, a percepção de qualidade de serviços pelos consumidores pode ser dividida em cinco critérios: tangibilidade, confiabilidade, atendimento, segurança e empatia. Dessa forma, a percepção de qualidade baseia-se em aspectos objetivos e subjetivos, sofrendo influência de diversos fatores, dentre os quais podemos destacar a classe econômica. Este estudo busca analisar a relação entre a classe econômica e a percepção de qualidade do consumidor no setor de serviços odontológicos. Para mensurar a percepção de qualidade, foi adotada a escala SERVQUAL adaptada e, para identificar a classe econômica, utilizou-se o Critério Brasil 2008 recomendado pela ABEP. Após a aplicação dos questionários, os dados foram transformados em estatística no Excel e se estabeleceu uma relação por meio de gráficos entre a classe econômica e o desempenho percebido para cada dimensão. Em seguida, os resultados foram confrontados com as teorias dos autores, de forma que comprovaram as teorias de Zeithaml et al. (1990 apud LOVELOCK; WRIGHT, 2006), e de Lemme, Noronha e Resende (1991), que tratam, respectivamente, da importância da dimensão confiabilidade na percepção

\footnotetext{
1 Andrea Dornelles Fittipaldi é cirurgiã-dentista graduada pela Universidade de Brasilia - UnB (2008), especialista em Radiologia Odontológica e Imaginologia pela Associação Brasileira de Odontologia - ABO-DF (2010), e bacharel em Administração pelo Centro Universitário de Brasília - UniCEUB (2011).

2 Carolina Lopes Araujo é professora do quadro permanente da Universidade de Brasília, campus Planaltina. Mestre em Administração pela Escola de Altos Estudos Comerciais da Universidade de Montreal, Canadá (HEC - Montreal) e bacharel em Administração pela Universidade Federal de Minas Gerais. Atualmente, é doutoranda em Desenvolvimento Sustentável na UnB.
} 
de qualidade pelos clientes e a influência do nível econômico dos clientes nas suas exigências e expectativas. Assim, é de extrema importância que as empresas procurem entender os fatores que influenciam a percepção do consumidor para serem capazes de atender às suas expectativas e mantê-lo satisfeito. E para se alcançar o objetivo maior, que é manter e fidelizar o consumidor, todo o trabalho da empresa deve estar voltado para o consumidor. Atualmente, existe uma enorme carência de análises de marketing e gestão no setor odontológico, mas esse quadro deve mudar em face das transformações que a odontologia vem sofrendo e da necessidade de fidelizar os pacientes.

Palavras-chave: Odontologia. Satisfação. Percepção de qualidade. Classe econômica.

\section{Introdução}

Esta pesquisa foi realizada na área de Administração de Marketing e tem como objetivo principal analisar a relação entre percepção de qualidade e classe social para serviços odontológicos. Para se alcançar o objetivo principal, foi necessário estabelecer os seguintes objetivos específicos: definir os conceitos de serviços e de qualidade; identificar as características específicas dos serviços de saúde; identificar os atributos de qualidade; estabelecer como os atributos de qualidade são percebidos pelos consumidores; elucidar o conceito e definir as categorias de classe econômica; identificar as classes econômicas dos consumidores; e relacionar os atributos de qualidade percebidos com as classes econômicas.

O problema de pesquisa que impulsiona este projeto questiona se existe diferença de percepção de qualidade com relação ao serviço odontológico entre diferentes classes econômicas.

Quando se trata de comportamento de seres humanos, muitos fatores estão envolvidos e não existe uma única fórmula para se fazer previsões. Segundo Silverstein e Stalk Júnior (2001), os consumidores são multifacetados e é importante que se atente para essa complexidade. Porém, reconhecendo essa limitação 
do trabalho, este estudo ficará restrito à classe econômica como fator influenciador do comportamento do consumidor e à satisfação como critério de medida da qualidade do serviço. Não serão objetos de estudo os outros fatores influenciadores e os modelos para controle de qualidade.

Conhecer a percepção dos clientes sobre a qualidade dos serviços permite que os profissionais direcionem suas estratégias e ações e tenham embasamento para entender e atender às expectativas dos clientes (FADEL; REGIS FILHO, 2005). Dessa forma, a pesquisa de marketing fala pelo consumidor (SILVERSTEIN; STALK JÚNIOR, 2001) e permite que as empresas criem estratégias de marketing e de gestão mais adequadas e eficientes.

Conhecer as atitudes dos clientes também permite conhecer o comportamento para compra e pós-compra, isso ajuda os gerentes a preverem comportamentos, aceitações e rejeições e a avaliarem conceitos de produtos, propagandas e promoção (MATTAR, 2001).

Finalmente, do ponto de vista social, analisar a relação entre percepção de qualidade e classe social é complexo, porém de grande valor para a sociedade e para os profissionais do marketing. A possibilidade de pacientes provenientes de classe de baixa renda e baixa escolaridade expressarem a satisfação e insatisfação com o atendimento odontológico legitima a importância de suas opiniões para a manutenção de um serviço de qualidade (LEMME; NORONHA; RESENDE, 1991).

Nas empresas, realizar pesquisas para identificar as reclamações dos clientes é fundamental antes de se projetar e implantar estratégias de melhoria de qualidade, pois esta é uma tarefa onerosa. Com os resultados em mãos, fica mais fácil definir prioridades e buscar as técnicas de melhoria de qualidade que trarão os melhores retornos financeiros (LOVELOCK; WRIGHT, 2006).

O estudo está embasado em estudo bibliográfico e pesquisa de campo, com aplicação de um questionário na Clínica Odontológica Só Riso, localizada no município de Ceilândia, no Distrito Federal. 
Esse trabalho é estruturado em cinco partes: na primeira parte, o tema é introduzido. A segunda parte apresenta uma revisão de literatura, citando estudos relacionados ao tema. Na terceira parte, são explicados a metodologia da pesquisa, o tipo da pesquisa e as técnicas utilizadas para coletar e analisar os dados. $\mathrm{Na}$ quarta parte, os resultados encontrados são discutidos. E, por fim, a quinta parte estabelece considerações finais e sugestões para pesquisas futuras.

\section{Revisão de Literatura}

\subsection{Marketing}

Marketing é definido por McDaniel e Gates (2003, p. 25) como “[...] o processo de planejar e executar a concepção, o apreçamento, a promoção e a distribuição de idéias, bens e serviços para criar trocas que satisfaçam os objetivos individuais e organizacionais".

Já para Kotler (2005, p. 27), marketing é “[...] um processo social e gerencial pelo qual indivíduos e grupos obtêm o que necessitam e desejam através da criação, oferta e troca de produtos de valor com outros”.

Os profissionais do marketing, na verdade, não criam necessidades, mas despertam e influenciam as necessidades, desejos e demandas já existentes. E, para se alcançar o objetivo maior, que é manter e fidelizar o consumidor, todo o trabalho da empresa deve estar voltado para ele (KOTLER, 2005).

Segundo Ambrósio (1999), McCarthy criou um modelo de marketing que atualmente é o mais usado no mundo empresarial: o composto de marketing, ou mix de marketing. Esse modelo coloca o consumidor no alvo de todos os esforços de marketing e estabelece que existem quatro elementos essenciais de marketing: produto, praça, promoção e preço. Para McDaniel e Gates (2003) a primeira tarefa que uma empresa deve realizar é identificar o mercado-alvo para, em seguida, adaptar seu mix de marketing para a clientela que almeja alcançar. Esse mix deve ser alterado ao longo do tempo para se adaptar às mudanças no mercado consumidor. 
Mas então, como se faz para entender o mercado?

Segundo McKenna (2004), para entender o mercado, os gerentes de marketing devem utilizar uma combinação de intuição e perspicácia. Intuição, aqui, não deve ser vista como algo negativo, e sim como uma forma de conhecimento baseado na experiência.

Atualmente, as empresas estão aprendendo que mais importante do que publicidade ou relações públicas é estabelecer uma comunicação aberta com o cliente, gerando experiência positiva e confiança. Na era do cliente, a comunicação é tão importante quanto o produto. E se comunicar com o cliente significa tanto falar quanto ouvir (MCKENNA, 2004).

Muitas empresas estão melhorando o seu processo de captação de reclamações de clientes por meio de questionários ou até linhas telefônicas. Dessa forma, as reclamações são documentadas, e os problemas são identificados e corrigidos. É bom lembrar que a empresa não deve ignorar as avaliações, pois isso pode acarretar em prejuízos (LOVELOCK; WRIGHT, 2006).

Um exemplo de prejuízo com danos irreparáveis para a empresa é a perda de clientes. Calcula-se que o custo para atrair novos clientes é cinco vezes maior do que o de manter satisfeitos os clientes já estabelecidos. Por isso, atualmente, maior ênfase está sendo dada à retenção e satisfação dos clientes (KOTLER, 2005).

Se o cliente está satisfeito e encantado com o serviço recebido, permanece fiel, apesar de surgirem ofertas atraentes dos concorrentes. Ele ainda pode trazer novos clientes para a empresa ao compartilhar seu entusiasmo com terceiros. Por outro lado, um cliente insatisfeito, ou indiferente, pode trazer problemas para a empresa, porque além de ser facilmente atraído pela concorrência, se a experiência tiver sido muito negativa, esse cliente pode disseminar impressões negativas para os outros (LOVELOCK; WRIGHT, 2006).

O segredo para fidelizar está em estabelecer relações sólidas baseadas na confiança, receptividade e qualidade. E ainda, para conquistar uma posição du- 
radoura no mercado, as empresas devem estabelecer relações fortes não somente com os consumidores, mas também com os fornecedores, distribuidores, revendedores, pessoas influentes no setor e membros da comunidade financeira (MCKENNA, 2004).

Para explicar as etapas que as empresas devem percorrer para atender melhor aos seus clientes e gerar fidelização, foi criado o termo Marketing de Relacionamento (LOVELOCK; WRIGHT, 2006, p. 132) que envolve “[...] atividades destinadas a desenvolver ligações economicamente eficazes de longo prazo entre uma organização e seus clientes”.

\subsection{Serviços}

Serviço é qualquer ato que uma parte oferece para outra, por meio de relações mercadológicas. Deve ser intangível e não resultar em propriedade de nada e pode ou não estar relacionado a um produto físico (KOTLER, 2005).

Os serviços estão presentes em todos os momentos da vida de um ser humano, desde o nascimento até a morte, e nas últimas décadas, vem ocorrendo um grande crescimento desse setor na economia. O crescimento no setor de serviços não para e está longe de encontrar uma fase de maturidade, até mesmo em países desenvolvidos (COBRA, 2001).

Os serviços possuem quatro características principais (KOTLER, 2005; LAS CASAS, 1999, p. 24):

1. Intangibilidade: os serviços são abstratos e os clientes não podem ver o produto antes de comprar, então para reduzir as incertezas, os gerentes devem evidenciar a localização, os funcionários, os equipamentos e outros itens tangíveis da empresa.

2. Inseparabilidade: o serviço é produzido com o vendedor e o comprador frente a frente, de modo que tanto o fornecedor como o cliente participam da sua produção. 
3. Variabilidade (ou heterogeneidade): é impossível manter a qualidade constante de um serviço, pois ele varia de acordo com a pessoa que o executa e as condições do local. Algumas formas de minimizar essa variação são: fazer seleção e treinamento de pessoal, padronização de processos e monitoração da satisfação do consumidor.

4. Perecibilidade (ou simultaneidade): o serviço é produzido e consumido ao mesmo tempo, assim, o serviço não pode ser estocado. Esse pode ser um fator complicador quando a demanda é flutuante.

O setor de serviços envolve tarefas complexas e pode apresentar problemas durante sua prestação. Segundo Parasuraman, Zeithaml e Berry (1985 apud KOTLER, 2005), existem quatro itens que podem causar problemas na prestação de serviços: lacuna entre as expectativas do consumidor e a percepção da empresa; lacuna entre a percepção da empresa e as especificações da qualidade do serviço; lacuna entre a execução do serviço e as comunicações externas; e lacuna entre o serviço percebido e o esperado.

A concorrência está cada dia mais acirrada, exigindo das organizações posturas agressivas para preservar e conquistar mercado. Segundo Cobra (2001), a globalização, ao aumentar a oferta estrangeira, cria algumas dificuldades para as organizações, dentre as quais podemos citar a necessidade de acompanhar a evolução tecnológica e o perfil dos clientes para identificar e atender às suas necessidades o mais rápido e corretamente possível, e a dificuldade para fidelizar clientes.

A fidelidade à marca de produtos e serviços tem diminuído no mundo inteiro; na área de serviços, a lealdade é ainda mais difícil de ser conseguida devido à sua característica de intangibilidade (COBRA, 2001).

\subsection{Serviços odontológicos}

Os serviços na área da saúde têm características específicas e muito diferentes dos outros serviços. Para Souza, Griebeler e Godoy (2007), isso acontece devido à sua ligação intrínseca com a vida humana. 
France e Grover (1992 apud SOUZA; GRIEBELER; GODOY, 2007, p. 436) fazem a seguinte afirmação: “[...] serviços de saúde são, provavelmente, os mais intangíveis de todos os serviços, pois, além de não poder experimentar o serviço previamente à compra, o consumidor, freqüentemente, não pode avaliá-lo, mesmo após o consumo".

Com base em Kotler (2005), é possível fazer algumas distinções em relação ao serviço odontológico: o serviço é baseado em pessoas, exige a presença do cliente e atende necessidades pessoais, logo, deve ser customizado.

Na Odontologia, podemos destacar uma característica particular: o medo. As pessoas ainda têm medo de dentista, e esse medo é atribuído ao paradigma cirúrgico-restaurador que predomina até hoje, em que é dada mais atenção à doença do que à saúde. Nesses tipos de atendimento, o profissional só realiza tratamentos extensos e dolorosos na boca do paciente, e este associa a dor à imagem do profissional (COSTA et al., 2008).

A tensão também pode gerar problemas para o cirurgião-dentista, tais como:

[...] dificuldade do condicionamento e cooperação do paciente durante o tratamento; prejuízo na relação profissional/paciente; exigências de maiores cuidados do profissional durante o planejamento e execução dos procedimentos clínicos. (FERREIRA et al., 2004, p. 54).

Além disso, a Odontologia tem passado, na última década, por grandes transformações. Costa et al. (2008) identificaram alguns fatos preocupantes, tais como a desvalorização e banalização da profissão, a visão reducionista ao dente, o alto custo e a falta de ética da concorrência. Eles também comentam que, apesar de o objetivo principal da profissão ser satisfazer às necessidades de saúde bucal das pessoas, ao longo do seu desenvolvimento, ocorreu uma acentuada divisão técnica e a Odontologia se manteve elitista e pouco resolutiva. 


\subsection{Qualidade}

O termo qualidade tem uma história muito antiga e já recebeu várias definições. Inicialmente, a ideia de qualidade era enfocada nos recursos produtivos, nas relações humanas ou no desempenho da empresa. Atualmente, na moderna administração, o ponto de partida para definir qualidade é o cliente. Essa perspectiva focada no cliente está presente no item "adequação ao uso", expressão criada por Juran (1988 apud MAXIMIANO, 2006). Neste trabalho, é dado enfoque aos conceitos da administração moderna que colocam os consumidores em primeiro plano.

Para Juran (1988 apud MAXIMIANO, 2006), a expressão "adequação ao uso" tem dois significados: qualidade de projeto e ausência de deficiências. Ambos requerem clientes satisfeitos com o desempenho dos produtos e serviços. Esses significados podem ser identificados nos estudos de Lovelock e Wright (2006) e de Campos (1992). Os primeiros definem qualidade como a qualidade de projeto, ou seja, focam no desempenho da empresa e na competitividade, enquanto Campos (1992) concentra-se na ausência de deficiências, na eficiência, nos custos e no tempo.

De acordo com Campos (1992), o objetivo principal de qualquer empresa é satisfazer às necessidades das pessoas, tanto dos consumidores, fornecendo qualidade, quanto dos empregados, dos acionistas e dos vizinhos da empresa. Ou seja, para satisfazer às necessidades dos consumidores, deve-se fornecer qualidade a todos os stakeholders. E, dessa forma, englobam-se todos os grupos ou indivíduos afetados direta ou indiretamente pela busca dos objetivos de uma organização (STONER; FREEMAN, 1985).

\subsection{Qualidade de serviços e satisfação dos clientes}

Na literatura, os conceitos de qualidade de serviço e de satisfação do cliente são muito próximos, porém não devem ser confundidos.

Para Lovelock e Wright (2006, p. 106), a percepção de qualidade pelo cliente é baseada "em avaliações cognitivas de longo prazo", enquanto a satisfação é "uma reação emocional de curto prazo". Dessa forma, a percepção de qualidade dos 
clientes vai sendo formada por experiências próprias de satisfação ou insatisfação com o serviço e também por opiniões de terceiros e propagandas.

Fadel e Regis Filho (2005) completam essa ideia, afirmando que a percepção da qualidade se baseia tanto em fatores objetivos quanto subjetivos. Enquanto, qualidade de serviço, para Lovelock e Wright (2006, p. 102), “[...] é o grau em que um serviço atende ou supera as expectativas do cliente".

Neste tema, um novo termo está em voga, é o retorno sobre a qualidade, um objetivo administrativo que estabelece que "[...] a qualidade entregue deve ser a desejada pelo mercado-alvo e a qualidade agregada deve causar um impacto positivo na lucratividade" (MCDANIEL; GATES, 2003, p. 10).

Já para Campos (1992, p. 2), “[...] um produto ou serviço de qualidade é aquele que atende perfeitamente, de forma confiável, de forma acessível, de forma segura e no tempo certo às necessidades do cliente". Ou seja, o projeto deve ser perfeito, com baixos custos, garantindo segurança para o cliente, e a entrega deve ser feita no prazo, no local e na quantidade certa.

Campos (1992) apresenta o modelo administrativo de Controle da Qualidade Total e afirma que, para verificar se uma empresa atingiu a Qualidade Total, é preciso medir o número de reclamações dos clientes, de produtos ou serviços defeituosos, os custos, os atrasos de entrega, o índice de absenteísmo etc. Os objetivos do Controle da Qualidade Total são: identificar as necessidades dos consumidores e realizar um planejamento para atendê-las; manter a qualidade desejada pelos clientes; e melhorar a qualidade desejada pelos clientes por meio da solução de problemas.

Dessa forma, Campos (1992) defende que, para garantir a qualidade no processo de produção, não basta atender às expectativas dos clientes, mas deve-se analisar falhas para prevenir defeitos, realizar manutenção preventiva, localizar problemas e lidar com eles.

Por outro lado, Souza, Griebeler e Godoy (2007) são mais radicais afirmando que oferecer produtos e serviços de qualidade deixou de ser diferencial com- 
petitivo e atualmente é condição de existência no mercado. Também comentam a necessidade de se realizar uma mensuração periódica da avaliação do consumidor para que os serviços sejam continuamente melhorados.

Para avaliar essa percepção de qualidade pelos clientes, existem vários modelos teórico-conceituais na literatura, mas ainda não se chegou a um consenso em relação ao ideal para cada setor da economia (SALAZAR; COSTA; RITA, 2005; ESPERIDIÃO; TRAD, 2006).

\subsection{Critérios de qualidade}

Um diferencial competitivo para empresas prestadoras de serviço é a qualidade percebida por seus clientes, ou seja, quando as expectativas dos clientes são atendidas ou excedidas em suas relações com a empresa. Portanto, é essencial que as empresas entendam aos critérios de avaliação dos consumidores. Existem algumas práticas comuns que um serviço deve apresentar para ser considerado de excelência; dentre elas podemos citar: padrões de qualidade, monitoramento de desempenho do serviço, atendimento às reclamações de consumidores, e ênfase na satisfação dos funcionários e dos consumidores (KOTLER, 2005).

Parasuraman, Zeithaml e Berry (1991) estabelecem um modelo em que os consumidores percebem a qualidade dos serviços de acordo com cinco critérios: tangibilidade, confiabilidade, atendimento, segurança e empatia. Para Las Casas (1999), o cliente percebe no serviço fatores tangíveis e intangíveis, ou seja, fatores físicos como a estrutura física do local e fatores de relacionamento interpessoal.

Esses mesmos autores Parasuraman, Zeithaml e Berry, citados em Kotler (2005), estabelecem três abordagens de criação de valor para gerar maior satisfação e confiança nos clientes: acréscimo de benefícios financeiros, de benefícios sociais e de vínculos estruturais. Os benefícios financeiros referem-se às recompensas para os consumidores que consomem grandes quantidades. Os sociais, à individualização e personalização dos relacionamentos entre a empresa e os consumidores. 
E os vínculos estruturais acontecem quando a empresa fornece instrumentos que ajudam os clientes a utilizarem os seus serviços.

\subsection{Expectativa e satisfação do consumidor}

Na literatura, o conceito de satisfação está ligado ao conceito de expectativa, variando de forma inversa (LOVELOCK; WRIGHT, 2006). Colocando isso em uma fórmula, é possível chegar à seguinte equação:

Satisfação = Serviço percebido/Serviço esperado

Expectativas existem em qualquer indivíduo antes de ele conhecer um produto ou serviço. Essas são formadas ou influenciadas por diferentes fatores, tais como experiência própria anterior, informação de terceiros, propaganda, promessas, preço, aparência das instalações e funcionários. As expectativas também podem variar de acordo com o sexo da pessoa, idade e cultura (LOVELOCK; WRIGHT, 2006; KOTLER, 2005). Dessa forma, funcionam como “[...] padrões internos que os clientes utilizam para julgar a qualidade de uma experiência de serviço" (LOVELOCK; WRIGHT, 2006, p. 103).

Após conhecer um produto ou serviço, o consumidor faz uma relação entre as suas expectativas e o desempenho percebido. Isso gera um sentimento de prazer ou desapontamento, que é também chamado de satisfação ou insatisfação (KOTLER, 2005). Dessa forma, o conceito de satisfação é pessoal e tem natureza subjetiva e por isso os estudos estão cada vez mais estabelecendo relações entre satisfação e fatores psicossociais (ESPERIDIÃO; TRAD, 2006).

Lovelock e Wright (2006) estabelecem um modelo de expectativas do cliente com os seguintes conceitos:

- serviço desejado: nível de serviço que o cliente acredita que pode e deve ser entregue;

- serviço adequado: nível mínimo de serviço para não gerar insatisfação; 
- serviço previsto: nível de serviço que o cliente acredita que será entregue de fato; $\mathrm{e}$

- zona de tolerância: variação de nível de serviço aceita pelos clientes.

Então, quando o serviço recebido é superior ao nível desejado, o cliente percebe como qualidade superior; quando o serviço recebido cai na zona de tolerância, é percebido como adequado; mas se o serviço cai em um nível inferior ao adequado, acontece uma lacuna na qualidade. Assim, para melhorar a qualidade de um serviço, é necessário estreitar essa lacuna o máximo possível.

\subsection{Qualidade em serviços odontológicos}

Mirshawka (1994 apud SOUZA; GRIEBELER; GODOY, 2007), classifica a qualidade no serviço de saúde nestes três tipos: qualidade clínica, referente à equipe de saúde e aos conceitos de saúde pública; qualidade voltada para o cliente, que destaca aspectos interpessoais para a satisfação das expectativas dos pacientes; e qualidade econômica, relacionada aos aspectos financeiros.

O estudo de Souza, Griebeler e Godoy (2007) se concentra nas dificuldades que os pacientes têm para avaliar os serviços na área da saúde. Os autores citam Santos, que afirma que o consumidor se baseia na sua qualificação para julgar a qualidade de um serviço. Quando ele se depara com produtos ou serviços tecnicamente complexos, sobre os quais não possui conhecimento técnico suficiente, passa a utilizar outras dimensões para avaliá-los. Gemmel et al. (2002 apud SOUZA, GRIEBELER; GODOY, 2007, p. 436) defendem que o paciente julga a qualidade do serviço de saúde baseado na evidência de preocupação dos profissionais com a sua saúde e bem-estar. Desse modo, entendem que "[...] a avaliação da qualidade em saúde é mais subjetiva que objetiva”.

Outros autores também comentam os aspectos subjetivos da avaliação da qualidade dos serviços. Para Martins (1997, p. 41)

[...] a qualidade de um serviço assistencial está diretamente associada à qualidade da relação interpessoal que ocorre entre os pacientes e os profissionais encarregados da assistência 
Ansuj, Zenckner e Godoy (2005) comentam que o julgamento da qualidade do serviço odontológico pelos pacientes é baseado principalmente nos aspectos pessoais, porém o profissional não deve esquecer que a qualidade técnica é uma exigência do serviço.

Além dos aspectos subjetivos na percepção de qualidade pelos pacientes, também devemos citar os critérios objetivos. Para Leão e Dias (2001), os requisitos avaliados no serviço odontológico são os seguintes: custo do tratamento, nível de dor, habilidades e atitudes do profissional, acesso e informações.

\subsection{Instrumentos de avaliação da qualidade percebida}

Segundo Mattar (2001), desenvolver um instrumento de coleta de dados em marketing é fundamental para a pesquisa alcançar o sucesso. De acordo com $\mathrm{McDa}$ niel e Gates (2003), a pesquisa de marketing, quando realizada adequadamente, traz inúmeras vantagens, por exemplo: ajuda os gerentes a entenderem o que está acontecendo no mercado e a aproveitarem as oportunidades, também auxilia no estabelecimento da visão, da missão, e na utilização de recursos em longo prazo.

Medir a satisfação de usuários pode ter muitas funções, sendo que as principais são descrever a percepção deles e avaliar a qualidade dos serviços. Porém, o conceito de satisfação é eminentemente subjetivo e falta consenso entre os autores quanto às variáveis que a influenciam. Essa fragilidade teórico-conceitual do termo faz com que os modelos voltados para medir a satisfação sejam vagos, de baixa predição e validação externa. É sabido que todo modelo teórico é parcial e aproximativo, mas as críticas feitas às medidas de satisfação devem ser levadas em conta para que seja encorajada uma validação para o seu conceito e para um instrumento de medida (ESPERIDIÃO; TRAD, 2006).

Ross, Steward e Sinacore (1995) afirmam que, apesar de os instrumentos de medida baseados na satisfação não serem confiáveis e poderem fornecer resultados errôneos, a satisfação do paciente é atualmente reconhecida pelos profissionais de saúde como um fator de medida legítimo da qualidade do serviço de saúde. 
A avaliação da satisfação de usuários traz benefícios. Segundo Esperidião e Trad (2006), particularmente nos serviços de saúde, ela permite estudar as relações interpessoais e funciona como instrumento de controle social. Ela também revela a preocupação dos profissionais com relação à satisfação e à fidelização do paciente; isso gera ganhos para a continuidade e a efetividade do tratamento.

Ainda de acordo com Esperidião e Trad (2006), a teoria mais utilizada nas pesquisas é a teoria da discrepância, que se baseia na diferença entre as expectativas e a percepção da experiência. Um exemplo de modelo desenvolvido com base nessa teoria é a escala SERVQUAL.

Segundo Nyeck et al. (2002), atualmente, a escala SERVQUAL é o modelo mais completo para medir e conceituar qualidade. Essa escala é muito popular e tem sido muito utilizada nos últimos anos, devido à sua facilidade de utilização e à sua adaptabilidade em diferentes setores da economia. Além disso, Hercos e Berezovsky (2006) afirmam que essa escala já está bem documentada e é autorizada para avaliar a qualidade em serviços de saúde.

A escala SERVQUAL se baseia nas expectativas e percepções dos pacientes e permite avaliar as cinco dimensões da qualidade de serviço: tangibilidade, confiabilidade, atendimento, segurança e empatia (HERCOS; BEREZOVSKY, 2006; LOVELOCK; WRIGHT, 2006).

Para entender melhor cada dimensão, podemos aplicar o conceito de serviço de qualidade máxima as cinco dimensões da escala SERVQUAL. Assim, é possível concluir que um serviço odontológico excelente tem as seguintes características (LOVELOCK; WRIGHT, 2006):

- No aspecto tangível: equipamentos modernos, instalações físicas atraentes e limpas, e funcionários com aparência impecável.

- No aspecto confiabilidade: o serviço é realizado corretamente já na primeira vez, os prazos são cumpridos, e os funcionários demonstram interesse em solucionar os problemas. 
- No aspecto sensibilidade: os funcionários sempre estão dispostos a ajudar e a atender aos pedidos.

- No aspecto segurança: os funcionários são constantemente gentis, têm conhecimento para responder perguntas e instigam segurança nos clientes.

- $\quad$ No aspecto empatia: o dentista entende as necessidades específicas de seus clientes, dá atenção individualizada e tem horários flexíveis.

\subsection{Classificação socioeconômica}

O marketing é um processo que tem dentre os seus objetivos definir mercados e quantificar as necessidades de cada segmento de mercado. E, "[...] para que esse processo seja efetivo, as organizações precisam ser orientadas para o consumidor/cliente" (MCDONALD, 2004, p. 87).

Comumente, é utilizado o método demográfico para descrever os clientes e consumidores. Esse método utiliza como critérios de classificação dos clientes a idade, o sexo, o nível de educação, o estágio no ciclo de vida da família e o grupo socioeconômico (A, B, C1, C2, D, E) a que pertencem (MCDONALD, 2004).

De acordo com Kotler (2005), conhecer as características do consumidor é o primeiro passo para conhecer o seu comportamento de compra. O autor estabelece quatro fatores que influenciam o comportamento de compra:

1. Fatores pessoais: idade, estágio do ciclo de vida, ocupação, situação econômica, estilo de vida, personalidade e autoestima.

2. Fatores psicológicos: motivação, percepção, aprendizagem, crenças e atitudes.

3. Fatores culturais: cultura, subcultura e classe social.

4. Fatores sociais: grupo de referência, famílias, papéis e posições sociais.

A influência que o nível econômico dos consumidores pode causar na sua percepção de qualidade e satisfação é demonstrada no estudo de Lemme, Noronha e Resende (1991). E ressalte-se que o nível econômico é um dos critérios que divide a sociedade em classes sociais (KOTLER, 2005). 
A sociedade é dividida em classes sociais de acordo com vários critérios, tais como renda, ocupação, nível educacional e área residencial. As classes sociais podem ser então definidas como "[...] divisões relativamente homogêneas e duradouras de uma sociedade, que são organizadas hierarquicamente e cujos membros compartilham valores, interesses e comportamentos similares" (KOTLER, 2005, p. 183). As pessoas pertencentes a uma classe tendem a apresentar comportamentos parecidos e podem trocar de classe durante a sua vida, mas isso depende da rigidez da estratificação social (KOTLER, 2005).

A Associação Brasileira de Empresas de Pesquisa (ABEP, 2009) afirma que é pouco esclarecedora a classificação da população por classes sociais e estabelece um critério de classificação em classes econômicas que é denominado Critério Brasil (CCEB), que estima o poder de compra dos indivíduos com base no Levantamento Sócio-Econômico do IBOPE, que é feito anualmente para mapear características sociais, demográficas e econômicas das metrópoles brasileiras.

Neste estudo, optou-se por utilizar a classificação indicada pela ABEP (2009). O Critério Brasil 2008 estabelece oito classes econômicas (A1, A2, B1, B2, C1, C2, D e E) distribuídas de acordo com a renda média familiar.

\section{Método de pesquisa}

Segundo Gil (2006, p. 26), método é “[...] o caminho para se chegar a determinado fim", e método cientifico é "[...] o conjunto de procedimentos intelectuais e técnicos para se atingir o conhecimento".

Esta pesquisa é explicativa, pois esclarece os fatores que contribuem para a ocorrência de um fenômeno (VERGARA, 2000) e aprofunda o conhecimento da realidade (GIL, 2002).

Os principais dados utilizados para responder ao problema de pesquisa são dados primários, coletados junto aos pacientes da Clínica Só Riso, localizada na cidade satélite de Ceilândia-DF. A empresa possui, em seu corpo clínico, dentistas 
de diferentes especialidades, como: Dentística, Prótese, Ortodontia, Oclusão, Periodontia e Cirurgia. Dessa maneira, o universo da pesquisa é o grupo de pacientes que, nesta clínica, se encontram em diferentes tipos e fases de tratamento. Em sua maioria, esses pacientes moram nas proximidades do local de atendimento.

A coleta de dados foi feita por meio de levantamento (survey), procedimento que interroga diretamente as pessoas para conhecer um determinado comportamento. O levantamento é muito eficaz para este tipo de estudo, porque permite conhecer a realidade de forma rápida e econômica e permite ainda que os resultados sejam quantificados (GIL, 2006). O instrumento de coleta de dados utilizado nesta pesquisa foi a escala SERVQUAL, para medir a percepção de qualidade. Para identificar a classe socioeconômica do paciente, foi utilizado o sistema de pontos do Critério Brasil, estabelecido pela ABEP (2009).

Foi feita uma abordagem pessoal com os pacientes enquanto eles aguardavam na sala de espera dos consultórios da Clínica Só Riso. Foram distribuídos questionários e canetas para o preenchimento. $\mathrm{O}$ pesquisador fez uma breve apresentação da pesquisa para contextualizar os entrevistados acerca dos objetivos e facilitar a participação e colaboração. A amostra foi definida pelo critério não probabilístico de acessibilidade (VERGARA, 2000), sendo composta por 60 pacientes, o que representa $15 \%$ do universo de 400 pessoas em tratamento atualmente.

Após a aplicação dos questionários, os dados foram tabulados no Excel e foram submetidos à análise estatística e à representação em gráficos. Desse modo, o tratamento dos dados foi de caráter quantitativo.

Para o cálculo do desempenho percebido, foi utilizada a seguinte fórmula matemática (HERCOS; BEREZOVSKY, 2006):

Desempenho percebido $=$ Atendimento recebido - Atendimento ideal

A escala SERVQUAL é classificada como uma escala social, pois mede a intensidade das opiniões e atitudes das pessoas, da maneira mais objetiva possível, e fornece dados de natureza quantitativa. 
O questionário é composto de duas partes. A primeira parte procura identificar a percepção de qualidade dos entrevistados e é baseada no questionário SERVQUAL modificado, o qual se sustenta nos cinco indicadores de qualidade de serviço mencionados anteriormente, ou seja: tangibilidade, confiabilidade, atendimento, segurança e empatia.

A escala SERVQUAL utiliza 23 questões divididas nas cinco dimensões, e os clientes julgam os itens em uma escala de 1 a 7 pontos que representam o grau de concordância com uma frase afirmativa que lhes é apresentada. A menor pontuação da escala refere-se à avaliação de discordância completa com a afirmativa (discordo inteiramente), e a mais alta pontuação refere-se à resposta "concordo inteiramente". A última questão do questionário busca ter acesso à percepção de qualidade geral pelo paciente.

A segunda parte do questionário busca identificar o perfil socioeconômico do entrevistado. Para tanto, foram utilizadas questões fundamentadas no Critério Brasil 2008, recomendado pela ABEP. O questionário se baseia no poder de compra e consumo das pessoas; para tanto, identifica o número de televisões, rádios, banheiros, automóveis, empregadas mensalistas, máquinas de lavar, videocassetes, DVDs, geladeiras e freezers que a pessoa ou a família possui. Além disso, é questionado o grau de instrução do chefe da família. Todos esses itens estabelecem pontos a serem somados. Por fim, a pontuação encontrada deve ser relacionada na tabela da ABEP (2009) para se verificar o provável enquadramento do respondente a uma classe econômica e uma renda familiar.

\section{Tratamento de dados}

Após a aplicação dos questionários, os dados foram transportados para o Excel e então foram construídas seis planilhas referentes aos seguintes fatores: grau de instrução, classe social, dimensões da qualidade, atendimento ideal, atendimento recebido e desempenho percebido.

Na planilha grau de instrução, foi anotada a resposta de cada respondente. Então se construiu uma tabela com os valores absolutos e relativos em porcen- 
tagem a cada grau de instrução, e a partir dela, foi feito um gráfico. E o mesmo aconteceu com a planilha de classe social, porém, para se determinar a classe econômica de cada respondente, foi necessário seguir os passos estabelecidos pelo Critério Brasil 2008.

Nas dimensões da qualidade, o respondente deveria estabelecer valores de importância para cada indicador de modo que os cinco juntos somassem cem. Esses números foram repassados para o Excel para se fazer uma tabela com os valores absolutos e relativos atribuídos a cada dimensão. Em seguida, foi construído um gráfico.

Nas planilhas do atendimento ideal e do atendimento recebido, foram colocados os valores respondidos pelos entrevistados, e na planilha de desempenho percebido, foi feita a subtração do primeiro sobre o segundo. Em seguida, as questões foram divididas de acordo com o indicador abordado e foi feito o cálculo das médias para cada questão, respondente e dimensão.

Após relacionar os entrevistados às suas respectivas classes econômicas, foi possível classificá-los e calcular uma média de satisfação para cada uma das classes econômicas a que pertenciam os respondentes. Com esses valores, construiu-se o gráfico desempenho percebido X classe econômica para cada dimensão.

\section{Apresentação e discussão dos resultados}

Os dados mostraram que $50 \%$ da amostra pesquisada pertencem à classe $\mathrm{B} 2,44 \%$ à classe $\mathrm{C} 1,3 \%$ à $\mathrm{B} 1$ e $3 \%$ à $\mathrm{C} 2$. Nenhum paciente entrevistado pertence às classes A1, A2, D e E. Dessa forma, de acordo com o Critério Brasil e considerando que 93\% dos entrevistados pertencem às classes B2 e C1, a renda estimada da amostra varia entre $\mathrm{R} \$ 1.195,00$ e $\mathrm{R} \$ 2.013$. É interessante comentar que o Critério Brasil 2008 estabelece que essas duas classes juntas correspondem a 36\% da população do DF.

Quanto ao grau de instrução da amostra, houve um predomínio do colegial completo ou superior incompleto (52\%), seguido pelo ginasial completo ou cole- 
gial incompleto (40\%), superior completo (5\%) e primário completo ou ginasial incompleto (3\%). Nenhum entrevistado é analfabeto ou possui primário incompleto.

Alocando pontos para cada dimensão da qualidade de serviço (tangibilidade, atendimento, segurança, empatia e confiabilidade), é revelado que os entrevistados dão maior importância para a confiabilidade (25\%) e a segurança (22\%) e menor importância para a empatia e o atendimento.

Os 23 itens do questionário SERVQUAL podem ser divididos de acordo com a dimensão abordada, de modo que as questões de 1 a 4 referem-se à tangibilidade, 5 a 9 confiança, 10 a 13 atendimento, 14 a 17 segurança, 18 a 22 empatia e 23 qualidade geral. A avaliação de qualidade para cada questão foi calculada subtraindo-se o desempenho percebido do ideal, em seguida, foram calculadas as médias de todos os entrevistados.

O indicador confiabilidade foi o que apresentou menor grau de satisfação, com média de -1,65, seguido pelo atendimento e tangibilidade. Dentre as questões de confiabilidade, é nítida uma menor satisfação nos itens que se referem ao cumprimento de horários marcados e de prazos de execução.

O maior grau de satisfação se encontra no indicador empatia, com média de $-1,06$, e no item 19, que corresponde à necessidade de a clínica funcionar em horários adequados aos seus pacientes, com -0,88.

É possível observar que a diferença entre a avaliação da empresa e a situação ideal é semelhante para todos os indicadores de qualidade de serviço, apresentando uma média de discreta insatisfação de -1,28.

Conforme visto anteriormente, os pacientes da amostra pertencem a quatro classes econômicas: B1, B2, C1 e C2. Relacionando esses grupos com as cinco dimensões de qualidade, notam-se diferenças significativas no desempenho percebido.

A primeira dimensão de qualidade demonstra a satisfação do paciente em relação aos aspectos tangíveis, tais como as facilidades físicas, equipamentos e 
apresentação da equipe. A segunda se refere a aspectos que geram confiança no paciente e à habilidade da clínica em realizar o serviço prometido de forma precisa e confiável. A terceira remete à receptividade da equipe, disposição para ajudar o consumidor e fornecer atendimento com prontidão. A quarta dimensão demonstra a satisfação do consumidor em relação ao conhecimento e cortesia dos funcionários e à habilidade deles em inspirar segurança. Já a quinta revela a percepção do consumidor em relação à atenção individualizada recebida na clínica. Por último, existe uma sexta dimensão que mostra a satisfação geral do consumidor (BABAKUS; MANGOLD, 1992).

A classe B1 se mostrou mais insatisfeita no aspecto segurança e empatia, com médias de -4,25 e -4, respectivamente. Já as classes B2, C1 e C2 estavam mais insatisfeitas com o aspecto confiabilidade.

Esses dados confirmam o estudo de Zeithaml et al. (1990 apud LOVELOCK; WRIGHT, 2006). Segundo o estudo, a dimensão confiabilidade é a mais importante na percepção de qualidade pelos clientes e é a única dimensão que não pode ser avaliada durante a entrega do serviço, somente depois. Ele ainda afirma que um serviço não confiável é percebido como deficiente e incompetente e que, para se garantir um serviço confiável, as empresas devem minimizar os erros e estabelecer uma padronização de processos para os funcionários.

Por outro lado, a insatisfação da classe B1, em relação ao indicador empatia, remete à importância de a área de saúde dar maior enfoque aos benefícios sociais. Isso pode ser visto nas três abordagens de criação de valor de Berry e Parasuraman que foram comentadas anteriormente, apresentadas em Kotler (2005). Segundo os autores, os pacientes se tornam mais satisfeitos quando são tratados pelo nome, como indivíduos únicos e importantes, por profissionais devidamente preparados. Ansuj, Zenckner e Godoy (2005) ainda comentam que, no atendimento, os pacientes se sentem mais seguros e respeitados quando são recebidos com presteza e cortesia, e consideram de grande relevância a segurança do profissional em relação ao tratamento.

Estabelecendo gráficos de desempenho para os indicadores de qualidade, percebe-se um padrão em que a satisfação cresce inversamente proporcional à classe 
econômica do paciente. Ou seja, a satisfação com relação ao desempenho do serviço tende a diminuir com o aumento da classe econômica do indivíduo. Quando se estabelece uma média de satisfação para cada classe social, pode-se notar que a classe C2 apresenta um valor de 0,95, a classe C1 -0,84, a classe B2 -1,65 e a classe B1 -3,42.

É importante frisar que somente a classe C2 apresenta valores positivos de satisfação, revelando que o serviço recebido superou as suas expectativas. As demais classes possuem valores negativos de satisfação, mostrando que as expectativas não foram atendidas. A classe B1 mostrou ser a mais exigente.

Segundo Lemme, Noronha e Resende (1991), vários autores já comprovaram que existe uma tendência por parte dos usuários de classes sociais menos favorecidas de avaliar positivamente os serviços que lhes são prestados. O estudo desses autores também chegou à mesma conclusão. A pesquisa buscava mensurar a satisfação de alunos, profissionais e pacientes com relação à qualidade do atendimento odontológico em um hospital universitário, mas foi identificada uma divergência. Os alunos e profissionais, pertencentes a um nível econômico mais alto, possuíam maiores exigências e expectativas.

Já para McDonald (2004), os grupos socioeconômicos estão perdendo a relevância como previsores de comportamento, e estão ganhando relevância os fatores contextuais, como por exemplo, bem-estar e conscientização, e os estágios da vida, como solteiros e idosos.

Também é possível estabelecer uma relação entre o grau de instrução e a satisfação. O estudo de Hercos e Berezovsky (2006) revela que existe uma tendência em que quanto maior o nível de escolaridade dos pacientes, maior é a insatisfação com o atendimento recebido.

\section{Considerações finais}

Os resultados alcançados revelam que, para se alcançar um serviço odontológico de qualidade, $25 \%$ dos entrevistados acreditam que o critério mais impor- 
tante é a confiabilidade, seguido pela segurança. Quando se estabelece uma média de satisfação para cada classe social, pode-se notar que existe um padrão em que a satisfação cresce inversamente proporcional à classe econômica do paciente. Além disso, a única classe que apresentou valores positivos de satisfação, revelando que o serviço recebido superou as suas expectativas, foi a classe mais baixa da amostra (C2), mostrando ser a menos exigente.

Para mensurar a satisfação do consumidor, é necessário que a empresa integre os dois fatores que a compõem: a expectativa e o desempenho percebido. Como a satisfação está diretamente ligada à percepção de qualidade, é preciso considerar as várias influências que afetam a satisfação dos pacientes de serviços odontológicos, dentre as quais destacamos a classe econômica.

O paciente de clínica odontológica dá grande importância para o indicador confiabilidade e demonstra que a sua avaliação tem aspectos tanto objetivos quanto subjetivos. Mattar (2001) comenta que medir atitudes é uma tarefa muito complexa, porque as atitudes existem na mente das pessoas e não são diretamente observáveis. Além disso, é muito relevante o momento em que essas atitudes são medidas.

Neste estudo, o questionário foi aplicado em sala de espera de consultório odontológico, momento esse de tensão e insegurança para a maioria dos pacientes. Esse fato pode ter gerado alteração na percepção, expectativa e satisfação do consumidor, todavia este tema foge do proposto.

O instrumento SERVQUAL foi o escolhido para este estudo devido à sua eficácia para avaliar qualidade em serviços de saúde (HERCOS; BEREZOVSKY, 2006), porém esse instrumento tem sido alvo de críticas na área de Marketing. Para Myerscough (2002), deveriam ser utilizados diferentes critérios no momento da expectativa de um serviço de qualidade e no momento da percepção da performance, porque são diferentes os fatores envolvidos.

O questionário SERVQUAL original é estrangeiro e precisou ser adaptado para a realidade cultural e socioeconômica do país e para o setor de Odontologia. Para tanto, utilizou-se como referência o estudo de Hercos e Berezovsky (2006). 
A despeito das dificuldades e limitações, esta pesquisa introduz uma visão administrativa para um setor que apresenta enorme carência de análises de marketing e gestão. As relações sociais na Odontologia são pouco discutidas. Apesar disso, é fundamental que o profissional entenda a dinâmica delas e o contexto em que está inserido para que o atendimento seja exercido adequadamente (COSTA et al., 2008). A Odontologia está passando por transformações e é importante que o mercado esteja atento para se adaptar às novas realidades.

Por fim, este estudo fornece um panorama geral sobre a dinâmica do comportamento do consumidor e sobre a influência do fator econômico nessas questões. Este estudo também permite argumentar que as organizações devem dar mais atenção para as expectativas dos consumidores. Quando as expectativas são condizentes com o real desempenho do serviço, é mais provável que haja satisfação. Kotler (2005) afirma que também é válido subestimar os potenciais do produto antes, para gerar maior satisfação depois.

Desse modo, fica a sugestão para se realizar mais pesquisas de comportamento do consumidor em estabelecimentos da área de saúde com frequência constante, em vários períodos de tempo e com diferentes segmentos de mercado, porque o comportamento do consumidor é dinâmico. Os pacientes desejam ser ouvidos e a administração necessita de base para tomar decisões. Além disso, seria interessante a realização de pesquisas entre nichos mais diferenciados, confrontando classes sociais e culturais mais elevadas com outras mais carentes.

\section{Relationship between perceived quality and economic class dental service}

\section{Abstract}

In the service activities it is observed the challenge to retain customers due the intangibility, inseparability, variability and perishability that characterizes services themselves. For dental services, the difficulty is even greater. The customer loyalty is based on a set of satisfaction experiences perceived by customers as quality indicators. In this study, we used the model of Parasuraman, Zeithaml and Berry 
(1991), whereby the perception of service quality by consumers can be divided into five dimensions: tangibility, reliability, service, security and empathy. Therefore, the perception of quality in dental services is based on objective and subjective aspects those are influenced by a diversity of variables, among which it highlights the economic class of consumers. The present research seeks to identify the relation between economic class and customers perception of quality for dental services. In order to measure the perception of quality, an adaptation of SERVQUAL scale was applied. To identify the economic class of customers, the Brazil 2008 Criteria was used, as recommended by the Brazilian Association of Research Organizations (ABEP). Data collected using questionnaire was treated by statistical analysis into the Excel. The analysis compared graphics representation of economic class and perception of quality for each dimension. Then, the results were related to theory and reaffirm the theories of Zeithaml et al. (1990 apud LOVELOCK; Wright, 2006), and Lemme, Noronha and Resende (1991), which postulate, respectively, about the importance of the reliability in perceived quality by customers and about the influence of customers economic class in their demands and expectations. Thus, it is very important for dental services providers to know the variables, as economic class, that influence the perceptions of quality by customers, in order to meet their expectations and keep them satisfied. For the purpose to maintain and retain customers, it is very important, for all management decisions, to take in account the customers perception of quality. Nowadays, it is observed a great lack of marketing analysis and management in the dental services, but this situation should change in light of the changes that dentistry has suffered and the need to retain patients.

Keywords: Dental services, customer satisfaction, perception of quality, economic class.

\section{Referências}

AMBRÓSIO, Vicente. Plano de marketing: passo a passo. Rio de Janeiro: Reichmann \& Affonso Editores, 1999.

ANSUJ, Ângela Pellegrin; ZENCKNER, Clacir Londero; GODOY, Leoni Pentiado. Percepção da qualidade dos serviços de odontologia. In: ENCONTRO NACIONAL 
DE ENGENHARIA DA PRODUÇÃO, 25., 2005, Porto Alegre. Anais eletrônicos... Porto Alegre, 2005. Disponível em: < http://www.abepro.org.br/biblioteca/ ENEGEP2005_Enegep0207_1418.pdf >. Acesso em: 10 set. 2009.

ASSOCIAÇÃO BRASILEIRA DE EMPRESAS DE PESQUISA (ABEP). Atividades dos grupos de trabalho da ABEP, (C2003. Disponível em: <http://www.abep.org.br>. Acesso em: 5 set. 2009 .

BABAKUS, E.; MANGOLD, G. Adapting the Servqual Scale to Hospital Services: An Empirical Investigation. Health Service Research, Memphis, v. 26, n. 2, p. 767-786, Feb 1992. Disponível em: <http://www.ncbi.nlm.nih.gov/pmc/articles/ PMC1069855>. Acesso em: 20 out. 2009.

CAMPOS, Vicente Falconi. TQC: controle da qualidade total (no estilo japonês). 4. ed. Belo Horizonte: Fundação Christiano Otoni, 1992.

COBRA, M. Estratégias de marketing de serviços. São Paulo: Cobra, 2001.

COSTA, S. et. al. Representação social da odontologia: uma abordagem qualitativa junto aos graduandos da UNIMONTES. Revista Odonto Ciência, Porto Alegre, v. 23, p. 238-242, 2008.

ESPERIDIÃO, M. A.; TRAD, L. A. B. Avaliação de satisfação de usuários: considerações teórico-conceituais. Cadernos de Saúde Pública, Rio de Janeiro, v. 22, p. 1.267-76, Jun 2006.

FADEL, Marianella Aguiar Ventura; REGIS FILHO, Gilsée Ivan. Percepção da qualidade em serviços públicos de saúde. In: ENCONTRO NACIONAL DE ENGENHARIA DA PRODUÇÃO, 26, 2005, Fortaleza. Anais eletrônicos... Porto Alegre: 2005. Disponível em: < http://www.scielo.br/pdf/rap/v43n1/a02v43n1.pdf >. Acesso em: 11 mar. 2009.

FERREIRA, Cláudio Maniglia et.al. Ansiedade odontológica: nível, prevalência e comportamento. Revista Brasileira em Promoção da Saúde, Fortaleza, v. 17, n. 001, p. 51-55, set 2004. Disponível em: <http://redalyc.uaemex.mx/redalyc/src/inicio/ ArtPdfRed.jsp?iCve=40817102>. Acesso em: 11 ago. 2009.

GIL, Antônio Carlos. Como elaborar projetos de pesquisa. 4. ed. São Paulo: Atlas, 2002.

GIL, Antônio Carlos. Métodos e técnicas de pesquisa social. 5. ed. São Paulo: Atlas, 2006. 
HERCOS, Benigno Vicente Santos; BEREZOVSKY, Adriana. Qualidade do serviço oftalmológico prestado aos pacientes ambulatoriais do Sistema Único de Saúde SUS. Arquivo Brasileiro de Oftalmologia, Local, v. 69, n. 2, p. 213-219, abr. 2006.

KOTLER, Philip. Administração de marketing: análise, planejamento, implementação e controle. 5. ed. São Paulo: Atlas, 2005.

LAS CASAS, A. L. Qualidade total em serviços. São Paulo: Atlas, 1999.

LEÃO, A. T. T.; DIAS, K. Avaliação dos serviços de saúde prestados por faculdades de odontologia: a visão do usuário. Revista Brasileira de Odontologia em Saúde Coletiva, Brasília, v. 2, n. 1, p. 40-46, jan./jun. 2001.

LEMME, Antonio C.; NORONHA, Gerson; RESENDE, José B. A satisfação do usuário em hospital universitário. Revista de Saúde Pública, São Paulo, v. 25, n. 1, p. 41-46, 1991. Disponível em: <www.scielo.br/pdf/rsp/v25n1/09.pdf>. Acesso em: 10 set. 2009.

LOVELOCK, C.; WRIGHT, L.. Serviços: marketing e gestão. Tradução de Cid Knipel Moreira. São Paulo: Saraiva, 2006.

MARTINS, M. C. F. N. Relação profissional-paciente: subsídios para profissionais de saúde. Psychiatry Online, 1997. Disponível em: <http://www.polbr.med.br/ arquivo/cezira.htm>. Acesso em: 10 ago. 2009.

MATTAR, Fauze Najib. Pesquisa de marketing: edição compacta. 3. ed. São Paulo: Atlas, 2001.

MAXIMIANO, Antonio César Amaru. Teoria geral da administração: da revolução urbana à revolução digital. 6. ed. São Paulo: Atlas, 2006.

MCDANIEL, Carl; GATES, Roger. Pesquisa de marketing. São Paulo: Pioneira, 2003.

MCDONALD, M. Planos de marketing: planejamento e gestão estratégica, como criar e implantar. Rio de Janeiro: Elsevier, 2004.

MCKENNA, Regis. Marketing de relacionamento: estratégias bem-sucedidas para a era do cliente. Rio de Janeiro: Campus, 2004.

MYERSCOUGH, Mark A. Concerns about SERVQUAL's underlying dimensions. Issues in Information Issues, Illinois, v. 3, p. 462-470, 2002. 
NYECK, S. et al. 10 years of service quality measurement: reviewing the use of the SERVQUAL instrument. Cuadernos de Difusion, Lima, v. 7, n. 13, p. 101-107, Dec 2002.

PARASURAMAN, A.; BERRY, Leonard L.; ZEITHAML, Valarie A. Refinement and Reassessment of the SERVQUAL Scale. Journal of Retailing, v. 67, n. 4, p. 420450 set 1991 .

ROSS, C. K.; STEWARD, C. A.; SINACORE, J. M. A comparative study of seven measures of patient satisfaction. Medical Care, Chicago, v. 33, n. 4, p. 392-406, Apr 1995. Disponível em: <http://www.jstor.org/pss/3766330>. Acesso em: 11 ago. 2009.

SALAZAR, A. K.; COSTA, J.; RITA, P. A qualidade do serviço, as percepções dos consumidores e dos directores dos hotéis de 4 e 5 estrelas das cadeias hoteleiras em Portugal. In: ACTAS das XV Jornadas Hispano-Lusas de Gestão Científica. Sevilha, Espanha, 2005.

SILVERSTEIN, Michael J.; STALK JÚNIOR., George. Rompendo hábitos de consumo: potencializando as oportunidades com criatividade, flexibilidade e coragem. Rio de Janeiro: Campus, 2001.

SOUZA, A. M; GRIEBELER, D; GODOY, L. P. Qualidade na prestação de serviços fisioterápicos - estudo de caso sobre expectativas e percepções dos clientes. Revista Produção, São Paulo, v. 17, n. 3, p. 435-453, set./dez. 2007. Disponível em: <http:// www.scielo.br/pdf/prod/v17n3/a04v17n3.pdf>. Acesso em: 2 set. 2009.

STONER, J. A. F; FREEMAN, R. E. Administração. 5. ed. Rio de Janeiro: Pretince Hall do Brasil, 1985.

VERGARA, Sylvia Constant. Projetos e relatórios de pesquisa em administração. 3 . ed. São Paulo: Atlas, 2000. 


\section{Para publicar na revista Universitas Gestão e TI, entre no endereço eletrônico www.publicacoesacademicas.uniceub.br. Observe as normas de publicação, facilitando e agilizando o trabalho de edição.}

